\title{
Adjuvant chemotherapy for colorectal cancer: age differences in factors influencing patients' treatment decisions
}

This article was published in the following Dove Press journal:

Patient Preference and Adherence

22 August 2013

Number of times this article has been viewed

\author{
Mikaela L Jorgensen ${ }^{1,2}$ \\ Jane M Young ${ }^{1,2}$ \\ Michael J Solomon ${ }^{1,3}$ \\ 'Surgical Outcomes Research Centre \\ (SOuRCe), Sydney School of Public \\ Health, University of Sydney and \\ Sydney Local Health District, NSW, \\ Australia; ${ }^{2}$ Cancer Epidemiology and \\ Services Research (CESR), Sydney \\ School of Public Health, University \\ of Sydney, NSW, Australia; ${ }^{3}$ Discipline \\ of Surgery, University of Sydney, \\ NSW, Australia
}

Purpose: Older colorectal cancer patients are significantly less likely than younger patients to receive guideline-recommended adjuvant chemotherapy. Previous research has indicated that patient refusal of treatment is a contributing factor. This study aimed to identify potential barriers to adjuvant chemotherapy use in older patients by examining the associations between patient age, factors influencing chemotherapy treatment decisions, and preferences for information and decision-making involvement.

Patients and methods: Sixty-eight patients who underwent surgery for colorectal cancer in Sydney, Australia, within the previous 24 months completed a self-administered survey.

Results: Fear of dying, health status, age, quality of life, and understanding treatment procedures and effects were significantly more important to older patients (aged $\geq 65$ years) than younger patients in deciding whether to accept chemotherapy (all $P<0.05$ ). Reducing the risk of cancer returning and physician trust were important factors for all patients. Practical barriers such as traveling for treatment and cost were rated lowest. Older patients preferred less information and involvement in treatment decision making than younger patients. However, $60 \%$ of the older group wanted detailed information about chemotherapy, and $83 \%$ wanted some involvement in decision making. Those preferring less information and involvement still rated many factors as important in their decision making, including understanding treatment procedures and effects.

Conclusion: A range of factors appears to influence patients' chemotherapy decision making, including, but not limited to, survival benefits and treatment toxicity. For older patients, balancing the risks and benefits of treatment may be made more complex by the impact of emotional motivators, greater health concerns, and conflicts between their need for understanding and their information and decision-making preferences. Through greater understanding of perceived barriers to treatment and unique motivators for treatment choice, physicians may be better able to support older patients to make informed decisions about their care.

Keywords: preferences, views, decision making, adjuvant therapy, older, elderly

\section{Introduction}

Colorectal cancer (CRC) is the second most commonly diagnosed cancer in Australia, with those aged over 65 years accounting for two-thirds of all cases. ${ }^{1}$ Current clinical practice guidelines for CRC state that advanced age alone should not be used to exclude patients from being offered effective treatment. ${ }^{2}$ For fit older patients, adjuvant chemotherapy appears to achieve similar survival benefits with no greater toxicity than for younger patients. ${ }^{3,4}$ However, older patients are significantly less likely to be referred for and receive guideline-recommended adjuvant chemotherapy, even after adjusting for age-related factors such as comorbidity. ${ }^{5-7}$ While patient age is reported
Correspondence: Mikaela L Jorgensen Cancer Epidemiology and Services Research (CESR), Queen Elizabeth II Research Institute (D02), University of Sydney, NSW 2006, Australia

Tel +6I 290365419

Fax +61295153222

Email mikaela.jorgensen@sydney.edu.au 
to be a strong influence of both surgeons' and oncologists' recommendations for chemotherapy, ${ }^{8-10}$ patient-based factors also appear to contribute to differences in treatment rates. A proportion of patients refuse adjuvant chemotherapy, and these patients are significantly more likely to be older than those who accept treatment. ${ }^{5,11,12}$

Patients' preferences for chemotherapy in CRC have previously been examined by determining the amount of life cancer patients are willing to forgo to avoid treatment, ${ }^{13}$ the survival benefit needed to make chemotherapy worthwhile, ${ }^{14}$ and the recurrence rate at which patients will change their preference from surgery alone to surgery plus chemoradiation. ${ }^{15}$ Although the strength of patients' preferences has been explored, less is known about the processes that influence these preferences. Treatment-related determinants (eg, treatment benefits and toxicities) and patient characteristics appear to only partially explain cancer patients' preferences for adjuvant chemotherapy. ${ }^{16}$ Patient age is not a consistent predictor of preferences, ${ }^{16,17}$ yet the higher rate of treatment refusal in older cancer patients implies age differences in treatment decision making. As treatment decisions are often made in the highly stressful period following cancer diagnosis, cognitive and affective determinants such as fear have been suggested as possible predictors. ${ }^{16}$

A range of other factors that may influence patients' chemotherapy decisions has also been proposed, for example, physician opinion, family support, and quality of life (QOL). Such factors have been explored in a qualitative study of older patients with breast cancer ${ }^{18}$ and a survey of older patients with colon cancer. ${ }^{19}$ However, these studies involved only patients aged 65 years and over, making it difficult to determine whether the reported factors actually distinguish the decision-making processes of older patients from younger patients. Other research involving cancer patients of all ages $^{20,21}$ does not focus on determining age differences in treatment decision making. Greater understanding of factors that uniquely affect older patients' decisions to undergo treatment is needed to ensure optimal treatment and outcomes.

Preferences for information and decision making might also affect patients' decisions to accept treatment. Older patients appear to be at greater risk of being inadequately informed about their cancer and treatment, as they generally prefer to receive less information and to be less actively involved in making treatment decisions than younger patients. $^{22,23}$ Physicians may also underestimate the absolute numbers of older patients who prefer to be fully informed and involved in decision making, as patient age is often reported solely as a predictor of preferences. ${ }^{21,24}$ In a study of CRC patients aged over 70 years, about half preferred an active or collaborative role in treatment decision making. ${ }^{25}$ It has also been suggested that older people want specific information about treatment and side effects. ${ }^{26}$ To create a more complete picture of older patients' decision making, age differences in specific chemotherapy preferences and their relationship to other influencing factors should be determined.

Thus, the aim of this study was to identify potential barriers to adjuvant chemotherapy use in older patients by examining the associations between patient age, factors influencing chemotherapy treatment decisions, and preferences for information and involvement in treatment decision making.

\section{Materials and methods \\ Participants}

Participants were recruited from a single tertiary referral hospital in Sydney, Australia. Patients aged over 18 years who had been admitted for CRC surgery within the previous 24 months were invited to participate either during their hospital stay or during a follow-up appointment with their surgeon. Eligible patients had sufficient English skills to participate, did not have cognitive impairment, and were not currently receiving chemotherapy. A surgical team member provided the researchers with the details of patients who gave their consent to be approached. Patients were given written information and the survey to complete in their own time. Those who received the survey during a follow-up appointment were provided with a reply-paid envelope, and nonresponders were contacted at 2 weeks and 4 weeks. The study was approved by the Sydney South West Area Health Service Ethics Review Committee.

\section{Survey instrument}

A self-administered survey was developed to determine CRC patients' views on factors influencing chemotherapy treatment decisions, preferences for treatment information, and preferences for involvement in treatment decision making.

Using a $10 \mathrm{~cm}$ visual analog scale, participants were asked to rate how important various factors were (or would be) when deciding about chemotherapy treatment. The list of factors was based on a literature review and included items about survival, health impacts, opinion of others, practical barriers (eg, cost), and cognitive/affective aspects (eg, fear). Information preferences were measured using a modified version of the validated Cassileth Information Styles Questionnaire. ${ }^{27}$ Participants were asked to choose a statement that best described their general attitude toward information regarding their illness, as 
well as specific preferences for chemotherapy information, such as side effects, treatment progress, and effectiveness in other patients. Decision-making preferences were measured using the Degner and Sloan scale, ${ }^{28}$ where participants can choose between five decision-making styles. Participant characteristics (eg, age, sex, education, and comorbidity) were also obtained.

\section{Data analysis}

For the purposes of this analysis, participants were divided into "younger" ( $<65$ years) and "older" ( $\geq 65$ years). The age of 65 years was selected to divide the sample because (1) the median age of the sample was 66 years, and (2) this cut-off is frequently used to define older age. ${ }^{29}$

\section{Factors influencing chemotherapy treatment decisions}

A score for each factor was produced by measuring the distance from the lowest anchor point to the point that the participant marked on the scale, to the nearest half centimeter. To determine whether the importance of each factor differed significantly by age, mean scores for the older group were compared with mean scores for the younger group, using independent-samples $t$-tests. Mann-Whitney rank sum tests were also performed to determine whether any skewing to the high end of the scale affected these results. Because treatment preferences appear to become more favorable after the decision has been made to proceed with adjuvant chemotherapy, ${ }^{30}$ multiple regression was used to assess whether any age differences in the importance of factors remained significant after adjusting for received or planned adjuvant chemotherapy.

Mean scores were also used to rank the overall importance of factors in chemotherapy decision making. Factors were tabulated by highest to lowest importance for the older age group. As a measure of complexity of decision making, the mean number of factors that participants rated as "important" was calculated. Factors with a rating over 5 were considered "important," as this was the midpoint value of the visual analog scale ("not at all important" to "very important").

\section{Preferences for information and involvement in decision making}

$\chi^{2}$ tests were used to examine age differences in information and decision-making preferences. Participants could select from four possible responses for their preferences for general information about illness. The proportions of older and younger participants who preferred as much information as possible about their illness were compared. Eight questions assessed specific preferences for chemotherapy information. The difference in the proportions of younger and older participants who reported that they "needed" or "wanted" all detailed chemotherapy information was examined. There were five options for preferred level of involvement in treatment decision making. The proportions of older and younger participants preferring active or collaborative decision-making roles were compared..$^{28}$

\section{Associations between preferences and factors influencing decisions}

Specific associations between information and decisionmaking preferences and factors influencing decisions were examined. To determine whether those who preferred minimal treatment information felt that understanding was still important in their decision making, the mean of the two factors about understanding ("understanding what is going to happen during treatment" and "understanding the benefits and side effects") was calculated for all participants. A $t$-test was used to compare these mean scores between those who preferred not to have detailed information about chemotherapy and those who did.

To determine whether those who preferred less involvement in decision making still considered a range of factors when making treatment decisions, the mean number of factors rated as "important" (mean score $>5$ on a 10-point visual analog scale) was compared between those who preferred a passive role and those who preferred an active/collaborative role, using a $t$-test.

\section{Results}

Of 75 patients with CRC who consented to participate in the study, 68 returned the survey (91\%). The participants ranged in age from 25 years to 82 years, with a mean age of 64 years. More participants were male and most spoke English at home (see Table 1 for further details). Nonparticipants did not differ significantly from participants for any of the characteristics listed in Table 1, though nonparticipants were slightly older (67 years versus 64 years).

\section{Factors influencing chemotherapy treatment decisions}

Six factors were significantly more important to older patients than younger patients in deciding whether to have chemotherapy: "fear of dying from cancer" $(t[66]=7.07 ; P<0.001)$, "how unwell I am to start with" $(t[66]=3.87 ; P<0.001)$, 
Table I Characteristics of colorectal cancer patients responding to survey

\begin{tabular}{|c|c|c|c|}
\hline Characteristic & $\begin{array}{l}\text { Older } \\
\text { group } \\
\mathbf{n}(\%)\end{array}$ & $\begin{array}{l}\text { Younger } \\
\text { group } \\
\text { n (\%) }\end{array}$ & $P$-value ${ }^{a}$ \\
\hline Total participants & $35(5 I)$ & $33(49)$ & \\
\hline Age in years, mean (SD) & $73.9(4.8)$ & $53.6(9.1)$ & \\
\hline Male & $22(63)$ & $17(52)$ & 0.34 \\
\hline English spoken at home & $25(7 I)$ & $28(85)$ & 0.18 \\
\hline High school or tertiary & $14(40)$ & $24(73)$ & 0.007 \\
\hline Employed full or part time & $5(14)$ & $22(67)$ & $<0.001$ \\
\hline Private health insurance & $16(46)$ & $20(6 \mathrm{I})$ & 0.22 \\
\hline Lives alone & $14(40)$ & $5(15)$ & 0.02 \\
\hline One or more comorbidities & $27(77)$ & $14(42)$ & \\
\hline Site of cancer & & & 0.32 \\
\hline Colon & $20(57)$ & $14(42)$ & \\
\hline Rectum & $13(37)$ & $17(5 \mid)$ & \\
\hline Dukes stage of cancer & & & 0.79 \\
\hline$A$ & $5(14)$ & $4(12)$ & \\
\hline B & $14(40)$ & II (33) & \\
\hline C & II (3I) & $12(36)$ & \\
\hline $\mathrm{D}$ & $2(6)$ & I (3) & \\
\hline $\begin{array}{l}\text { Adjuvant chemotherapy } \\
\text { (received or planned) }\end{array}$ & $10(29)$ & $17(51)$ & 0.08 \\
\hline
\end{tabular}

Note: ${ }^{\text {aP }}$-values based on $\chi^{2}$ tests.

Abbreviation: SD, standard deviation.

"how old I am" $(t[63]=2.87 ; P=0.006)$, "maintaining a good QOL during treatment" $(t[66]=2.94 ; P=0.005)$, "understanding the benefits and side effects" $(t[66]=2.87$; $P=0.005$ ), and "understanding what is going to happen during treatment" $(t[66]=2.95 ; P=0.004)$. After adjusting for received or planned chemotherapy, all of these factors remained significant except for "how old I am" $(P=0.07)$.

"Reducing the risk of the cancer coming back" was the most highly rated item, on average, for both older and younger groups (see Table 2). "Having a doctor whose expertise I trust" and "having a doctor whom I feel comfortable asking questions of" both rated very highly. Another factor rated highly by both groups was "returning to my normal QOL after treatment." Factors of lowest importance were also comparable between age groups. Traveling for treatment and treatment cost and duration were rated low by both older and younger patients, and "avoiding side effects" and "the opinion of my family" were also of low importance.

On average, both groups rated nearly all of the 22 factors as "important" in chemotherapy decision making (ie, mean score $>5$ on a 10 -point visual analog scale). The older group rated more factors as "important" (mean [standard deviation $\{\mathrm{SD}\}]=18.1$ [3.1]) than the younger group (mean $[\mathrm{SD}]=16.7$ [3.6]) and had a slightly higher mean score for the importance of all factors ( 8.0 versus 7.4 ), but these differences were not significant.

\section{Preferences for information and involvement in decision making}

Fifty percent of older participants preferred to have as much information as possible about their illness, compared with $76 \%$

Table 2 Factors of importance in chemotherapy decision making ${ }^{a}$

\begin{tabular}{|c|c|c|c|}
\hline Factor & $\begin{array}{l}\text { Older group } \\
\text { mean (SD) }\end{array}$ & $\begin{array}{l}\text { Younger group } \\
\text { mean (SD) }\end{array}$ & $P$-value \\
\hline Reducing the risk of the cancer coming back & $9.3(0.5)$ & $9.3(0.8)$ & 0.44 \\
\hline Having a doctor whose expertise I trust & $9.2(0.5)$ & $9.2(0.6)$ & 0.49 \\
\hline Understanding the benefits and side effects & $9.2(0.7)$ & $8.5(1.3)$ & 0.02 \\
\hline Understanding what is going to happen during treatment & $9.2(0.6)$ & $8.1(2.2)$ & 0.02 \\
\hline Returning to my normal quality of life after treatment & $9.1(0.6)$ & $9.3(0.8)$ & 0.10 \\
\hline Having a doctor whom I feel comfortable asking questions of & $9.1(0.6)$ & $9.0(1.0)$ & 0.68 \\
\hline Maintaining a good quality of life during treatment & $9.1(0.7)$ & $8.1(2.0)$ & 0.04 \\
\hline The recommendation of the doctor & $9.0(0.9)$ & $8.6(1.2)$ & 0.19 \\
\hline Increasing my chance of living longer & $8.9(1.3)$ & $8.5(1.6)$ & 0.17 \\
\hline Doing everything possible to fight the cancer & $8.9(1.3)$ & $8.4(2.7)$ & 0.71 \\
\hline Fear of dying from cancer & $8.9(1.3)$ & $4.8(3.2)$ & $<0.001$ \\
\hline How unwell I am to start with & $8.5(1.5)$ & $6.0(3.6)$ & 0.03 \\
\hline Having someone to look after me during treatment & $7.9(2.5)$ & $6.8(2.8)$ & 0.13 \\
\hline Maintaining my independence & $7.8(2.5)$ & $8.4(1.5)$ & 0.70 \\
\hline Being able to look after significant others & $7.5(3.1)$ & $7.5(2.5)$ & 0.97 \\
\hline How old I am & $7.5(3.1)$ & $5.0(3.8)$ & 0.009 \\
\hline Having time to decide about treatment & $7.3(2.9)$ & $7.7(2.9)$ & 0.28 \\
\hline Avoiding side effects & $6.7(3.2)$ & $6.2(3.3)$ & 0.45 \\
\hline The opinion of my family & $6.7(3.6)$ & $6.0(3.0)$ & 0.21 \\
\hline Total duration of the treatment & $5.8(3.3)$ & $6.8(3.5)$ & 0.25 \\
\hline Cost of treatment & $5.5(3.6)$ & $5.5(3.6)$ & 0.81 \\
\hline How far I would have to travel for treatment & $3.8(2.8)$ & $5.5(4.0)$ & 0.05 \\
\hline Mean score of all factors & $8.0(1.0)$ & $7.4(1.4)$ & 0.27 \\
\hline
\end{tabular}

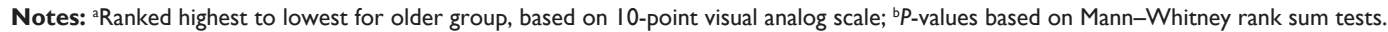
Abbreviation: SD, standard deviation. 
of younger participants $\left(\chi^{2}[1]=4.75, P=0.03\right)$. However, the majority of the older group reported wanting or needing as much detailed information about chemotherapy as possible $(60 \%)$, and this proportion was not significantly different from the younger group $(76 \%)\left(\chi^{2}[1]=1.93, P=0.17\right)$. Most patients from both the older and younger groups had a preference for some degree of involvement in decision making ( $83 \%$ and $91 \%$, respectively); no one expressed a preference for sole decision making. Although a greater proportion of younger participants preferred an active/collaborative role than older participants, this difference was not significant $\left(\chi^{2}[1]=2.37\right.$, $P=0.12$ ). These results are summarized in Table 3 .

\section{Associations between preferences and factors influencing decisions}

Participants who preferred to have detailed information about chemotherapy rated the understanding of treatment procedures and their effects as significantly more important in their decision making than those who preferred not to have detailed information (mean $[\mathrm{SD}]=9.1[0.9]$ versus 8.2 [1.7], $P=0.04)$. However, the high mean score (8.2) for those preferring not to have detailed information indicates that understanding treatment procedures and effects was still important for these participants.

Those who expressed a preference for involvement in decision making rated significantly more factors as "important" than those who preferred to leave all decisions about treatment to the doctor (mean $[\mathrm{SD}]=17.8$ [3.2] versus 14.9 [3.4], $P=0.01$ ). Although a significant difference, participants preferring to leave all decisions to the doctor still rated a mean 15 of 22 factors as "important" in their decision making.

\section{Discussion}

In this study, fear of dying, health status, age, QOL, and understanding treatment and its benefits and side effects were significantly more important to older patients than younger patients in deciding whether to accept chemotherapy. Reducing cancer recurrence and physician trust were highly important to both age groups, and practical barriers such as travel and cost were of low importance. Older patients preferred less information and less involvement in treatment decision making than younger patients. However, $60 \%$ of the older group still wanted detailed information about chemotherapy, and $83 \%$ wanted some degree of involvement in treatment decision making. Those preferring less information and less involvement in decision making still rated many factors as important in their decision making, including understanding treatment procedures and effects.

Much of the literature that investigates patient preferences for chemotherapy focuses on weighing survival benefit against treatment toxicity. ${ }^{31}$ That these preferences are difficult to predict on the basis of patient or treatment characteristics implies that other factors may influence patients' decisions to accept treatment. ${ }^{16}$ In our study, fear of dying was significantly more important to older patients than younger patients in deciding whether to have chemotherapy. Fear has been noted in other studies as both a barrier to adjuvant chemotherapy use ${ }^{20}$ and a factor involved in decision making generally. ${ }^{32}$ Although fear of death is typically reported to decrease with age, ${ }^{33}$ the greater fear of dying from cancer for older people in this study could stem from a historical belief that no treatment will work against cancer. This is a major concern, as those with higher levels of fear are more

Table 3 Patient preferences for information and involvement in decision making

\begin{tabular}{|c|c|c|c|}
\hline & $\begin{array}{l}\text { Older group } \\
\text { n (\%) }\end{array}$ & $\begin{array}{l}\text { Younger group } \\
\text { n (\%) }\end{array}$ & $P$-value \\
\hline Preference for information about illness & & & 0.03 \\
\hline As much information as possible, good and bad ${ }^{b}$ & $17(50)$ & $25(76)$ & \\
\hline Only the information needed to care for self properly & $4(12)$ & $6(18)$ & \\
\hline Additional information only if it is good news & $3(9)$ & $0(0)$ & \\
\hline Leave it up to the doctor & $10(29)$ & $2(6)$ & \\
\hline Preference for detailed information about chemotherapy & & & 0.17 \\
\hline Would like or need to have all detailed information ${ }^{\mathrm{b}}$ & $21(60)$ & $25(76)$ & \\
\hline Does not want all detailed information & $14(40)$ & $8(24)$ & \\
\hline Preference for treatment decision making & & & 0.12 \\
\hline Shared responsibility with doctor for decisions ${ }^{b}$ & $13(37)$ & $14(42)$ & \\
\hline Select treatment by self after seriously considering doctor's opinion ${ }^{\mathrm{b}}$ & $5(14)$ & $9(27)$ & \\
\hline Make final selection of treatment by self ${ }^{b}$ & $0(0)$ & $0(0)$ & \\
\hline Doctor makes final decision but considers their opinion & II (3I) & $7(21)$ & \\
\hline Leave all decisions about treatment to doctor & $6(17)$ & $3(9)$ & \\
\hline
\end{tabular}

Notes: a ${ }^{P}$-values based on $\chi^{2}$ tests; ${ }^{b}$ indicates grouping for significance testing of proportions. 
likely to avoid cancer information ${ }^{34}$ that could actually help to dispel negative expectations about chemotherapy use and cancer survival.

Attitudes toward aging may be another cognitive/ affective factor influencing treatment decisions. In our study, age was significantly more important in chemotherapy decision making for older patients than younger patients. Older physicians also appear to place greater importance on patient age than younger physicians. ${ }^{8,10}$ Although age alone may be an important consideration for the oldest old, even those aged 80-84 years can experience treatment-associated survival benefit, ${ }^{35}$ and current evidence supports the safety of adjuvant chemotherapy in fit older patients. ${ }^{4}$ Attitudes toward older age and treatment may change with the aging of the "baby boomer" generation, as this group appears to have high expectations for their health, longevity, and care. ${ }^{36}$ Until such a time, ensuring that both patients and physicians are aware of current research on the effectiveness of adjuvant chemotherapy for older adults could help to reduce the impact of attitudes on treatment receipt.

Practical barriers such as cost, duration, and traveling for treatment were factors of low importance for both older and younger participants in our study. Cost and travel were also factors that least influenced chemotherapy decisions in a previous survey of older patients with colon cancer. ${ }^{19}$ However, in a self-reported practice survey, traveling a long distance for adjuvant chemotherapy was the factor that most decreased the likelihood that surgeons would refer an older patient compared with a younger patient. ${ }^{8}$ Physician and patient views frequently differ in many aspects of treatment decision making. ${ }^{13,19,25}$ As emotional motivators appear to play a large role in patient preferences, and practical considerations such a small one, the question then arises whether patients are best placed to make difficult treatment decisions at such a highly stressful time. On the other hand, physicians may also make decisions based on their own attitudes, under the pressure of a finite health system where the benefits to older patients are much less clearly defined. Given the expected rise in the number of cancer cases due to population aging, these motivational and economic considerations deserve substantial attention.

Many of the other findings in this study are comparable to those of previous research in treatment decision making. Trust in the physician and physician recommendation, rated highly by the participants in our study, are often reported as important factors influencing treatment decisions. ${ }^{19,21}$ Reducing recurrence and increasing survival are the benefits against which risks are commonly weighed in patient preference studies, and these were factors that both age groups rated highly in our study. Function preservation and maintenance of QOL represent major goals for an increasing proportion of older patients. ${ }^{37}$ In our study, QOL and health status were indeed factors that older patients considered more important in their decision making than younger patients. Comorbid health status is similarly a key consideration in the treatment decisions of physicians. ${ }^{8-10}$ Although emerging evidence suggests that adjuvant chemotherapy does not substantially alter the QOL of older patients ${ }^{38}$ and can provide a significant survival benefit in some chronic conditions, ${ }^{39}$ further research is needed if QOL and comorbidity are to cease being barriers to treatment.

The preferences of older patients for information and involvement in decision making may also create a barrier to adjuvant chemotherapy use. Older patients are generally reported to prefer less information than younger patients and to prefer a more passive role in treatment decision making. ${ }^{22,23}$ This was the case in our study, with $40 \%$ not wanting detailed information about chemotherapy and $17 \%$ wanting to leave all treatment decisions to the doctor. However, older patients were actually significantly more likely than younger patients to report that both understanding treatment procedures and understanding treatment benefits and side effects were important factors in decision making. In addition, those participants preferring not to be involved in decision making still rated 15 of 22 factors as important considerations. Similar paradoxes have been reported elsewhere, ${ }^{24,26}$ and may help to explain why physicians have difficulty predicting patient preferences. ${ }^{25}$ It has been suggested that patients seek to understand the rationale behind doctors' recommendations rather than to make decisions themselves. ${ }^{40}$ Given that older patients have greater difficulty understanding and remembering the information they receive ${ }^{24,41}$ and may not feel comfortable asking questions of their physicians, ${ }^{23}$ the responsibility for ensuring that all patients are adequately informed and involved likely lies with physicians. Decision aids may be useful in increasing understanding, even where patients prefer a passive role in treatment decision making. ${ }^{42}$

This was a relatively small single-site study, and the results should be interpreted with caution. None of the participants in our study refused chemotherapy, and therefore insights into actual barriers for this population could not be explored. Nevertheless, the results largely match previous findings about the decision-making processes of older adults and further illuminate specific age differences in CRC patients' treatment decisions. 


\section{Conclusion}

A range of factors appears to influence patients' chemotherapy decision making, including, but not limited to, survival benefits and treatment toxicity. For older patients, balancing the risks and benefits of treatment may be made more complex by the impact of emotional motivators, greater health concerns, and conflicts between their need for understanding and their preferences for information and involvement in decision making. The variability in perceived barriers to treatment and preferences for information and involvement demonstrates the need for explicit and individualized assessment of both of these areas. Without formal assessment, physicians might assume that older patients would not travel for adjuvant chemotherapy or that they do not want information on their prognosis and treatment. Through greater understanding of perceived barriers to treatment and unique motivators for treatment choice, older patients may be better supported to make fully informed decisions about their care.

\section{Acknowledgments}

Thank you to all participants who took part in this research study, and to the members of their surgical teams.

\section{Disclosure}

Mikaela L Jorgensen was supported by a postgraduate scholarship from the Cancer Institute NSW. The other authors report no conflicts of interest in this work.

\section{References}

1. Australian Institute of Health and Welfare (AIHW). ACIM (Australian Cancer Incidence and Mortality) books. Canberra, Australia: AIHW; 2012. Available from: http://www.aihw.gov.au/acim-books/. Accessed July 22, 2013.

2. Australian Cancer Network Colorectal Cancer Guidelines Revision Committee. Guidelines for the prevention, early detection and management of colorectal cancer. Sydney, Australia: The Cancer Council Australia and Australian Cancer Network; 2005.

3. Sargent DJ, Goldberg RM, Jacobson SD, et al. A pooled analysis of adjuvant chemotherapy for resected colon cancer in elderly patients. N Engl J Med. 2001;345(15):1091-1097.

4. Papamichael D, Audisio R, Horiot JC, et al. Treatment of the elderly colorectal cancer patient: SIOG expert recommendations. Ann Oncol. 2009;20(1):5-16.

5. Ananda S, Field KM, Kosmider S, et al. Patient age and comorbidity are major determinants of adjuvant chemotherapy use for stage III colon cancer in routine clinical practice. J Clin Oncol. 2008;26(27): 4516-4517.

6. Etzioni DA, El-Khoueiry AB, Beart RW. Rates and predictors of chemotherapy use for stage III colon cancer: a systematic review. Cancer. 2008;113(12):3279-3289.

7. Quipourt V, Jooste V, Cottet V, Faivre J, Bouvier A. Comorbidities alone do not explain the undertreatment of colorectal cancer in older adults: a French population-based study. J Am Geriatr Soc. 2011;59(4): 694-698.
8. Jorgensen ML, Young JM, Solomon MJ. Older patients and adjuvant therapy for colorectal cancer: surgeon knowledge, opinions, and practice. Dis Colon Rectum. 2011;54(3):335-341.

9. Krzyzanowska MK, Regan MM, Powell M, Earle CC, Weeks JC. Impact of patient age and comorbidity on surgeon versus oncologist preferences for adjuvant chemotherapy for stage III colon cancer. $J \mathrm{Am}$ Coll Surg. 2009;208(2):202-209.

10. Keating NL, Landrum MB, Klabunde CN, et al. Adjuvant chemotherapy for stage III colon cancer: do physicians agree about the importance of patient age and comorbidity? J Clin Oncol. 2008;26(15): 2532-2537.

11. Landrum MB, Keating NL, Lamont EB, Bozeman SR, McNeil BJ. Reasons for underuse of recommended therapies for colorectal and lung cancer in the Veterans Health Administration. Cancer. 2012;118(13): 3345-3355.

12. El Shayeb M, Scarfe A, Yasui Y, Winget M. Reasons physicians do not recommend and patients refuse adjuvant chemotherapy for stage III colon cancer: a population based chart review. BMC Res Notes. 2012;7(5):269.

13. Harrison JD, Solomon MJ, Young JM, et al. Patient and physician preferences for surgical and adjuvant treatment options for rectal cancer. Arch Surg. 2008;143(4):389-394.

14. Blinman P, Duric V, Nowak AK, et al. Adjuvant chemotherapy for early colon cancer: what survival benefits make it worthwhile? Eur J Cancer. 2010;46(10):1800-1807.

15. Couture J, Chan R, Bouharaoui F. Patient's preferences for adjuvant postoperative chemoradiation therapy in rectal cancer. Dis Colon Rectum. 2005;48(11):2055-2060.

16. Jansen SJ, Otten W, Stiggelbout AM. Review of determinants of patients' preferences for adjuvant therapy in cancer. J Clin Oncol. 2004;22(15):3181-3190.

17. Stiggelbout AM, De Haes JCJM. Patient preference for cancer therapy: an overview of measurement approaches. J Clin Oncol. 2001;19(1): $220-230$.

18. Kreling B, Figueiredo MI, Sheppard VL, Mandelblatt JS. A qualitative study of factors affecting chemotherapy use in older women with breast cancer: barriers, promoters, and implications for intervention. Psychooncology. 2006;15(12):1065-1076.

19. Kutner JS, Vu KO, Prindiville SA, Byers TE. Patient age and cancer treatment decisions. Patient and physician views. Cancer Pract. 2000;8(3):114-119.

20. Bickell NA, Cohen A. Understanding reasons for underuse: an approach to improve quality and reduce disparities in breast cancer treatment. Mt Sinai J Med. 2008;75(1):23-30.

21. Salkeld G, Solomon M, Short L, Butow PN. A matter of trust: patient's views on decision-making in colorectal cancer. Health Expect. 2004;7(2):104-114

22. Pinquart M, Duberstein PR. Information needs and decisionmaking processes in older cancer patients. Crit Rev Oncol Hematol. 2004;51(1):69-80.

23. Ankem K. Factors influencing information needs among cancer patients: a meta-analysis. Libr Inf Sci Res. 2006;28(1):7-23.

24. Beaver K, Campbell M, Craven O, Jones D, Luker KA, Susnerwala SS. Colorectal cancer patients' attitudes towards involvement in decision making. Health Expect. 2009;12(1):27-37.

25. Elkin EB, Kim SH, Casper ES, Kissane DW, Schrag D. Desire for information and involvement in treatment decisions: elderly cancer patients' preferences and their physicians' perceptions. J Clin Oncol. 2007;25(33):5275-5280.

26. Jenkins V, Fallowfield L, Saul J. Information needs of patients with cancer: results from a large study in UK cancer centres. Br J Cancer. 2001;84(1):48-51

27. Cassileth BR, Zupkis RV, Sutton-Smith K, March V. Information and participation preferences among cancer patients. Ann Intern Med. 1980;92(6):832-836.

28. Degner LF, Sloan JA. Decision making during serious illness: what role do patients really want to play? J Clin Epidemiol. 1992;45(9):941-950. 
29. Orimo H, Ito H, Suzuki T, Araki A, Hosoi T, Sawabe M. Reviewing the definition of "elderly". Geriatr Gerontol Int. 2006;6(3):149-158.

30. Jansen SJ, Otten W, Baas-Thijssen MC, CJ VDV, Nortier HW, Stiggelbout AM. Stability of preferences with regard to adjuvant chemotherapy: impact of treatment decision, experience and the passing of time. Eur J Cancer Care (Engl). 2008;17(1):74-83.

31. Blinman P, King M, Norman R, Viney R, Stockler MR. Preferences for cancer treatments: an overview of methods and applications in oncology. Ann Oncol. 2012;23(5):1104-1110.

32. Zafar SY, Alexander SC, Weinfurt KP, Schulman KA, Abernethy AP. Decision making and quality of life in the treatment of cancer: a review. Support Care Cancer. 2009;17(2):117-127.

33. Russac RJ, Gatliff C, Reece M, Spottswood D. Death anxiety across the adult years: an examination of age and gender effects. Death Stud. 2007;31(6):549-561.

34. Miles A, Voorwinden S, Chapman S, Wardle J. Psychologic predictors of cancer information avoidance among older adults: the role of cancer fear and fatalism. Cancer Epidemiol Biomarkers Prev. 2008;17(8): 1872-1879.

35. Zuckerman IH, Rapp T, Onukwugha E, et al. Effect of age on survival benefit of adjuvant chemotherapy in elderly patients with stage III colon cancer. J Am Geriatr Soc. 2009;57(8):1403-1410.
36. Quine S, Carter S. Australian baby boomers' expectations and plans for their old age. Australas J Ageing. 2006;25(1):3-8.

37. Repetto L, Comandini D, Mammoliti S. Life expectancy, comorbidity and quality of life: the treatment equation in the older cancer patients. Crit Rev Oncol Hematol. 2001;37(2):147-152.

38. Bouvier AM, Jooste V, Bonnetain F, et al. Adjuvant treatments do not alter the quality of life in elderly patients with colorectal cancer: a population-based study. Cancer. 2008;113(4):879-886.

39. Gross CP, McAvay GJ, Guo Z, Tinetti ME. The impact of chronic illnesses on the use and effectiveness of adjuvant chemotherapy for colon cancer. Cancer. 2007;109(12):2410-2419.

40. Beaver K, Jones D, Susnerwala S, et al. Exploring the decision-making preferences of people with colorectal cancer. Health Expect. 2005;8(2): 103-113.

41. Posma ER, van Weert JCM, Jansen J, Bensing JM. Older cancer patients' information and support needs surrounding treatment: an evaluation through the eyes of patients, relatives and professionals. BMC Nursing. 2009;8:1.

42. Butow PN, Solomon M, Young JM, et al. Consumer impact of an interactive decision aid for rectal cancer patients offered adjuvant therapy. Colorectal Dis. 2006;8(8):676-682.
Patient Preference and Adherence

\section{Publish your work in this journal}

Patient Preference and Adherence is an international, peer-reviewed, open access journal focusing on the growing importance of patient preference and adherence throughout the therapeutic continuum. Patient satisfaction, acceptability, quality of life, compliance, persistence and their role in developing new therapeutic modalities and compounds to

\section{Dovepress}

optimize clinical outcomes for existing disease states are major areas of interest. This journal has been accepted for indexing on PubMed Central The manuscript management system is completely online and includes a very quick and fair peer-review system. Visit http://www.dovepress.com/ testimonials.php to read real quotes from published authors. 